\title{
The Innovation Discussion of Enterprise Management under E-Commerce Environment
}

\author{
Qiyu Liang \\ Hainan College of Economics and Business, China
}

Keywords: E-commerce, Enterprise management, Information management, Management innovation.

\begin{abstract}
With the development of science and technology and commercial level, e-commerce has become an important way many companies conduct business activities. However, on the basis of e-commerce, enterprise management and traditional management model under a big difference. Many businesses in this area encountered a problem. Enterprise management costs are too high and cannot react to changes in the market and so a series of questions. This paper describes the case of Dell, combined with some of the problems currently encountered by enterprises, targeted to the enterprise to make some comments and suggestions in both logistics and information management.
\end{abstract}

\section{Introduction}

In today's economic globalization, a modern enterprise facing is by no means an area or a country, but the whole world. As a result, the modern enterprise is facing a very realistic and serious problem, namely the modernization of enterprise management, the core content of modern management, including enterprise advanced culture mode of modernization, the modernization of enterprise management, enterprise managers, etc. , as a whole, the system, the concept of enterprise management modernization enterprise has a close relationship with whether can well adapt to the requirement of economic development in the new period, whether can better survival and development [1]. This time, the electronic commerce can embody its important role. E-commerce can provide guarantee for the modernization of enterprise management, help enterprises to realize the modernization of management method, management means, etc. Under this new way of business, enterprise customer relationship management, organizational culture, knowledge management, information resources management and soon have great changes will occur. Under the e-commerce environment management theory and methods of research, is an important topic in front of every enterprise.

\section{E-commerce development status at home and abroad}

The third industrial revolution, the world goes into the information era, the Internet technology rapid development. In the $90 \mathrm{~s}$, the Internet's new form, e-commerce has become a mainstream in the development of the Internet [1]. Electronic commerce is increasingly growing, directly promote informationalization, digital business activities. Electronic commerce reduced commodity circulation of the intermediate links, greatly reduce the cost of commodity circulation, make the terminal consumer more easy to get high quality cheap goods, consumers with little mouse can buy what you want.

2015 "government work report" to develop "Internet +" plan of action, to promote the mobile Internet, cloud computing, big data, combined with modern manufacturing industries such as the Internet of things, and to promote e-commerce, industrial development of the Internet and Internet financial health, it shows that under the action of the Internet e-commerce also has the very big development space. E-commerce is, however, depends on the efficient logistics system, logistics distribution is considered to be "the last kilometer" of e-commerce, the logistics development and load capacity of led directly to the consumer shopping experience and consumption of the viscosity, 
the electronic commerce enterprise's competition is a big part of the logistics link between competitions [1]. E-commerce enterprises to maximize the customer experience, where the strength of the self-built logistics, cross-border self-built logistics, such enterprises represented by Jingdong mall, vance; Express and logistics enterprises in order to expand business, to the greatest extent crossover also expand the business, such enterprises represented by the optimal motion.

\section{Basic concept of electronic commerce}

E-commerce is all sorts of electronically rather than face-to-face way to complete the transaction. E-commerce is the advanced application of information technology, used to enhance the commercial relationship between the trading partners. E-commerce is a kind of based on the information of the realization of the business idea, to improve the efficiency in the process of trade. E-commerce is a new mode of business [2]. Will be through the network of business together; make it possible to have the cooperation of all sorts of real and virtual. An all enterprises in the supply chain can become a harmonious cooperation as a whole, enterprise employees can also participate in the supplier's business processes in [2]. Retailers' sales terminals can be automatically connected to the supplier, no longer need to artificial link in purchasing department, purchase orders will be automatically confirmed and arrange the delivery. Enterprise can also through the new way to provide better service to customers, this is not a big enterprise can be achieved. The Internet provides new development opportunities for small and medium enterprises; any enterprise can with worldwide suppliers and customers to establish business relationship. The effective use of information has become a new economic pattern of the important means of enterprise competitiveness; e-commerce will become the basic trade and communications.

\section{The role of electronic commerce to the enterprise management}

The role of electronic commerce to the enterprise management thoughts. E-commerce broke through the regional, time limit, make the enterprise directly facing the global resources allocation, companies need to set up the concept of globalization [2]. Both at home and abroad, it does not matter is day or night. Just click on the website, you can know the dynamic information of enterprises and their product, as long as you open the E-mail can receive orders from global cutting, consulting information, just click on the online bank remittance to and receive remittances from various places around the world.

The role of e-commerce on enterprise management organization. Organization is an important aspect in enterprise management functions; management modernization is an important content of promoting enterprise management modernization. The traditional organization is a pyramid of top-down vertical structure. Traditional organization emphasizes the professional division of labor, order delivery, etc., in the rapid development of e-commerce in the information age is bloated and inefficient operation [2]. Refinement of traditional division of labor organization already cannot adapt to the needs of the development of electronic commerce. E-commerce requires enterprise management flat organization structure, decision diversification.

Electronic commerce to the enterprise management way and the method. With the development and the rise of e-commerce, enterprise has realized the new breakthrough in the field of management style, methods, and many of the traditional management way and method to upgrade, many new methods of management, emerge in endlessly [3]. In production management, ERP and so on as the platform of integrated management information system of each subsystem upgrade in the traditional mode of production. In each production stage after the implementation of e-commerce can connect with each other through the network, at the same time to make the traditional serial type production line into the parallel type of production under the network economy, to reduce a lot of unnecessary waiting time at the same time, realizing low inventory production.

The role of electronic commerce to the enterprise management. Modern management is effective measures to improve the management level of enterprises. Electronic commerce to the enterprise management of the biggest effect is the application of computer network. The computer is 
the foundation of e-commerce, is also the foundation of enterprise modernization of management methods the application of the computer [3]. Greatly improve the efficiency of the enterprise, has realized the real automation. Internet makes electronic commerce truly become a reality, thus become the most advanced enterprise management methods. Companies not only in the internal network, achieve information sharing, but also with the external network Taobao, form the Internet. Enterprises through the establishment of their own websites can make their own business ideas, business conditions, product information in a fully open position, make the zero distance contact with customers and enterprises, compared with traditional strong propaganda are more likely to develop the user's trust and loyalty to the enterprise. Management software applications, not only greatly saves the manpower and material resources of the enterprise, also can improve the efficiency of enterprises.

The role of e-commerce on enterprise management personnel. Electronic business need to manage talents with global speed innovation concept, this is the electronic commerce of large volume, high transmission speed. The second is the ability to modernization [4]. In the impact of electronic commerce in the organization, method, means and so on all have adapted to the new , this requires managers must have the corresponding professional knowledge quickly enough understanding, adaptation and into the electronic commerce environment can j e-commerce activities, and to learn and progress.

\section{The status quo of e-commerce application in enterprise management and development}

The status quo of e-commerce application in enterprise management. From the process of China's enterprise management, the present situations of the application of e-commerce and insufficient exist in many aspects to be improved [4]. These problems are mainly reflected in, for most of the small and medium-sized enterprise electronic commerce is still in concept, and because in the business environment within the confines of e-commerce to enterprises' management has a very big difficulty. Also is the enterprise to electronic commerce application level is relatively low, the application of e-commerce in enterprise management, and electronic degree have not reached equilibrium [4]. Many enterprises lack of awareness of Internet marketing in electronic commerce application.

The plight of e-commerce application in enterprise management development. Enterprise management in the process of developing e-commerce applications, there is a lot of difficulties to be solved, from the enterprise's own application development dilemma; the leadership of the enterprise in the information consciousness is still relatively weak. In the process of corresponding institutional Settings, shelter space, lack of network information resource department full-time staff hard to deploy, so usually part-time personnel for the network information collection, so in the professionalism of the work and efficiency level, support for the decision-making, there are certain problems [5]. There is the benefit of the enterprise application of electronic commerce has many restrictions, most companies are busy to live, how to in the application of e-commerce and network marketing has not been fully appreciated, so under the lack of resources and capital input, it is difficult to the electronic commerce effectively play a role in the enterprise management.

In addition, in the process of enterprise management, the application of electronic commerce development dilemma from the social perspective, mainly for network infrastructure construction has not been effectively improved. Electronic commerce is in the information network communication based on the development of business activities, it can be full attention in the construction of infrastructure, accordingly speed and high bandwidth in the network, to effectively meet the actual demand, on the hardware and software to provide fully [5]. But in the development of current China in this respect remains to be further perfected. Especially on the basis of the economic development imbalance, there are many differences in each region level; it is to the enterprise the use of e-commerce has a great influence. In addition, in the means of payment and the use of e-commerce security issues and legal aspects of the problems and issues such as taxes are applied to enterprise's electronic commerce also has a great influence. 
Finally, in the online trading of logistics problems and workers, their own professional quality problems, to enterprise's electronic commerce also have a big problem [5]. China hasn't development in logistics system, on the flow speed is relatively long, online delivery problems are more and more prominent.

\section{E-commerce in the enterprise management innovation}

Enterprise management process, the implementation of the electronic commerce is application innovation strategy, to be considering from various aspects, in the electronic commerce environment of the organization development of the enterprise to innovate, to develop toward a flatter organizational structure. The advent of the Internet age, the computer information technology has been widely used in the management of the enterprise, in the organizational structure of enterprise is to be combined with background of times development [6]. Through the flat organization structure can make enterprises to respond to market development agile and flexible. Can dialogue with customers directly and to meet the market demand will be able to effectively improve efficiency, in product design and processing, can effectively improve management level. They were in the middle management link to management efficiency has increased substantially. The application of e-commerce in innovation of enterprise supply chain management level effectively. Information technology and the change of the enterprise management concept make the enterprise competition manner and method also great changes have taken place, market competition is in one direction to work toward a multidirectional competition.

The application of electronic commerce to the enterprise played a significant role in human resource management mode innovation, can in the application of electronic commerce, the professional personnel training has a positive role [6]. E-commerce is a new technology application, so the enterprise in the development of electronic commerce application, will be sufficient attention to the cultivation of professional talents, establish a professional team, the application of computer hardware and software aspects such as personnel and automated communication technology personnel training has a promoting effect. In addition, in the process of enterprise management, the application of e-commerce can effectively promote risk management level [7]. Use of e-commerce, enterprises need to be able to form a strategic perspective, to the enterprise management of the risk to be able to have sufficient attention, through the application of electronic commerce, in the actual risk to strengthen defense. Through the electronic commerce application the actual effect, understand the overall situation of the management of enterprises in advance. Particular way is:

Turning e-commerce in one of the most important position. To give priority to with business, to the technology is complementary, the electronic commerce technology as a way to achieve business goals.

Speed up the construction of enterprise information. At present Chinese enterprise widespread information behind the basis of the status quo, and modernization of network and electronic commerce technology, formed the huge contrast is not adapt to even hindered the enterprise electronic commerce application and development in China [7]. That should accelerate the process of enterprise information infrastructure from multiple aspects.

To adapt to the combined with innovation. To be combined with the enterprise business requirements and technology two aspects. Enterprise electronic commerce general planning, determines the feasible business model.

Establishing large enterprises is the core of electronic commerce system. Large enterprises as the core, according to the relationship of supply chain to establish the enterprise electronic commerce system, and promoting small and medium-sized enterprise electronic commerce application and development, is China's enterprise electronic commerce application and development important way.

To open network spirit. E-commerce including enterprise internal, B2B, B2C, C2C and G2B mode of complex system, enterprise no matter what role in the e-commerce industry, no matter in what field, should be eyes wide, systems thinking, development of coexistence and cooperation, in the spirit of openness of the network into the era of network and e-commerce [7]. 
Establish comprehensive e-commerce sites. They can be the most mature computer buyers psychological needs, with our professional knowledge and information comprehensive, thorough and real-time, quick to master, provide consumers with absolute authority absolutely absolute professional considerate option, help them to realize rational shopping.

\section{Summary}

To sum up, the actual enterprise management in the process, due to affected by various factors, to promote the efficiency of management has a block. And the application of e-commerce in the process, can be collected timely to enterprise development, so as to solve practical problems of provides a good opportunity. Through the theoretical research on the application of the electronic commerce of enterprise management, have substantial significance to the promotion of enterprise's management level.

\section{References}

[1] H.X. Li, Introduction to e-commerce, Dalian, Northeast University of finance and economics press, 2008, vol. 3, pp. 10-13.

[2] G.B. Hong, E-commerce security and management, Beijing: electronic industry press, 2006, vol. 3, PP. 30-33.

[3] G.Y. Zhang, E-commerce and enterprise management, Beijing: Peking University press, 2009, vol. 5 pp. 21-26.

[4] Q. Z. Xia, Enterprise electronic commerce development strategy in China, Beijing: Peking University press, 2001, vol. 6, pp. 66-68.

[5] Ch. H. Li, E-commerce solutions, Beijing: Beijing Jiaotong University press, 2006, vol. 10, pp. 88-91.

[6] B.T. Dong, E-commerce systems analysis and design, Beijing: higher education press, 2003, vol. 7, pp. 22-26.

[7] Y.T. Lin, E-commerce impact on enterprise management and innovation, Enterprise management, 2011, vol. 8, pp. 14-17. 